\title{
UNIVERSUM

\section{MIGRACIÓN, DESPOJO Y AMORES PERDIDOS EN LAS TIERRAS ARRASADAS DE EMILIANO MONGE}

\author{
Migration, dispossession and lost loves in Emiliano Monge's Las tierras arrasadas
}

\begin{abstract}
Ricardo Ferrada Alarcón ${ }^{1}$ (iD
'Universidad Católica Silva Henríquez, Escuela de Educación en Castellano, Santiago, RM, Chile. Doctor en Estudios Americanos, Universidad de Santiago.

Wriverrada@vtrinet

\section{RESUMEN}

El centro de este trabajo refiere a las estrategias de ficcionalización que organizan el mundo narrado en Las tierras arrasadas (2015) de Emiliano Monge, en cuyo flujo narrativo se despliega, transtextualmente, la historia de una banda que trafica emigrantes, el discurso testimonial de quienes sobrevivieron a una matanza, más la inserción de fragmentos de "El infierno" de Dante. En ese contexto, el problema que se aborda en ese espacio ficcional es el sustrato que ordena la novela, en el que si bien atañe a la emigración, la intriga novelesca consiste en el enfrentamiento a muerte de bandas de traficantes humanos. En ese marco, se sostiene la premisa de que en Las tierras arrasadas se pone en discusión un orden social que ha naturalizado la violencia. Se concluye entonces que, a partir de la transtextualidad, se elabora un relato que desborda la novela y compromete el afuera de la palabra literaria, con lo cual Monge se adscribe a un grupo de escritores que proponen nuevas formas de escritura en Latinoamérica del siglo XXI.
\end{abstract}

PALABRAS CLAVE: migración; bandas; testimonio; transtextualidad; el afuera.

\section{ABSTRACT}

The center of this work refers to the fictionalization strategies that organize the narrated world in Emiliano Monge's Las tierras arrasadas (The destroyed lands) (2015), in whose narrative flow, transtextuality, the story of a gang that traffics migrants, the testimonial discourse of those who survived a massacre, plus the insertion of fragments from Dante's "Hell". In this context, the problem that is addressed in this fictional space is the substratum of the novel orders, in which, although it concerns emigration, the fictional intrigue consists in the confrontation to death of gangs of human traffickers. Within this framework, the premise is maintained that a devastated social order that has naturalized violence is being questioned in Las tierras arrasadas. It is concluded then that, from the transtextuality, a story is elaborated that goes beyond the novel and compromises the outside of the literary word, with which Monge is assigned to a group of writers who propose new forms of writing in Latin America of the $2 \mathrm{I}^{\text {st }}$ century.

KEYWORDS: migration; gangs; testimony; transtextuality; the outside.

Fecha de Recepción $2 \mathrm{O} 2 \mathrm{O}-\mathrm{OI}-3 \mathrm{I}$
Fecha de Evaluación 2020-04-09
Fecha de Aceptación

$2020-08-19$ 


\section{PRESENTACIÓN}

... la novela es una sintaxis, tan intrincada que produce una ilusión espacio-temporal. Pedro Ángel Palou (RCLL No 75 , 20I2: 484)

Los marcos conceptuales, si en principio procuran precisar las dimensiones que modelan un campo de estudio, no es menos cierto que, a su vez, perfilan líneas de análisis e interpretación. Sobre este punto, un desafío importante consiste en explorar el diseño de categorizaciones que ayuden a comprender, en este caso, al novelista Emiliano Monge, que se inscribe en el proceso narrativo latinoamericano entrado el siglo XXI, en la medida que es insuficiente afirmar que se pone a distancia de momentos previos como el llamado "posboom", o que evidencia una ruptura con tendencias canonizadas por la historia literaria. Cualquiera sea la perspectiva, de todos modos es inevitable considerar en este ámbito el espacio social, en tanto escritores como Monge, al constituir los mundos narrados, ponen en presencia temas en curso próximos a su inmediatez, además de la influencia de la modernización, que en general produce una cultura que se piensa globalizada, en cuyo centro operan cuestiones vinculadas a la economía y el influjo de las medios y las tecnologías, aunque sus efectos tengan un carácter muchas veces de orden local.

En términos de experiencia de lectura, se puede constatar que una parte significativa de la novela latinoamericana de las décadas iniciales del siglo XXI, hace notorio ese problema, esto es, la irrupción de una variada trama de conflictos que plantean nuevas dinámicas y visiones de mundo, como a su vez el hallazgo de formas inusuales de componer el texto, que recogen los cambios culturales. La narración potencia preguntas - dicen los escritores- antes que el cierre a una respuesta, asimismo - agregan - está lejos de constituir una cita de la realidad, aunque se le parezca en su nominalización.

En ese campo de reflexiones situamos el centro de este trabajo, esto es, el análisis de las estrategias de ficcionalización que organizan el mundo narrado en la novela Las tierras arrasadas (2015) de Emiliano Monge, donde la temática del desplazamiento migratorio prefigura la imposibilidad de su cumplimiento, en tanto su sentido utópico es roto por una trama asesina que los conduce a su muerte.

El problema que se aborda en ese espacio ficcional refiere al sustrato que secciona y ordena la novela (Libros e Intermedios), en el que si bien su núcleo narrativo tiene como intriga la confrontación entre bandas de tráfico humano, desde otro nivel, despliega, alternadamente, el discurso no ficcional de testimonios de migrantes que sobreviven a una matanza, cuya desolación se 
acentúa al ensamblarse en el flujo narrativo fragmentos de "El infierno" de Dante. A partir de esa perspectiva, cabe sostener que en Las tierras arrasadas se pone en discusión un orden social que ha naturalizado la violencia, dando forma a una cultura marginal, en que el sentido de lo humano se reduce a relaciones de dominio y de poder; consecuentemente, desde la transtextualidad se proponen las acciones de un relato que desborda el texto y compromete el afuera de la palabra literaria.

Para desarrollar el planteamiento anterior, se abordan primeramente consideraciones teóricas sobre narrativa latinoamericana a comienzos del siglo XXI, cuyo centro se orienta a problemas narratológicos, donde son claves las estrategias de ficcionalización, en cuanto se activan en el análisis. Visto lo anterior, luego se indaga en el mundo narrado de Las tierras arrasadas en dos apartados: "La ficción de la no-ficción" y "La acción de los intermedios", que de un modo provocativo, en definitiva, pone en discusión los conflictos que sobrelleva el problema de la migración en algunas regiones del continente.

\section{HACIA LAS FORMAS TRANSTEXTUALES EN NARRATIVA}

Acorde al planteamiento anterior, se entiende que la novela latinoamericana a comienzos del siglo XXI produce no solo modos de leer; también implica para el receptor el desafío de explorar en sus contenidos, acudiendo a dimensiones extratextuales que le aportan elementos de juicio con los cuales (re)elabora el mundo de palabras que se le propone. En ese proceso, desde su carácter ficticio, la novela direccionaría el nivel argumental de la narración hacia las condiciones que entregan verosimilitud a la realidad construida literariamente; en un concepto barthesiano, se propicia un "efecto de realidad". Acertadamente, Iván Jabonkla en La historia es una literatura contemporánea (2016) proyecta a esa idea el "efecto de presencia" que singulariza la narración en tanto discurso, un atributo que hace extensivo al discurso de la historia, en el interés de aproximarse a la verdad histórica.

En esos términos, el sentido que adquiere el mundo narrado, dada su estrategia de composición, pone en funcionamiento no solo un verosímil literario que funciona como realidad, sino que, además, un verosímil referencial, en cuanto el contenido del texto entrega información empírico-factual, esto es, enunciaciones de contenido verificable y que aportan conocimiento. Eso habilita el contacto de la palabra literaria con la realidad empírica, tránsito que genera un tipo de 
lectura en que las secuencias en torno a una historia producen imágenes que conectan con un "afuera".

El fondo de esa proposición consiste en que los mundos literarios requieren de ese trayecto por el afuera, que en paráfrasis con Foucault, "no se encuentra jamás en las cosas ni en los hombres, sino en la imposible verosimilitud de aquello que está entre ambos..." (2014: 27), que es precisamente el desafío del lector: poner en acto lo innombrado o sugerido. La narración permite preguntarse sobre la realidad, aunque sea un "simulacro" de la realidad como planteara Marthe Robert. El mismo Jabonkla ahonda más y señala que la historia narrativa revela la dimensión humana y sicológica de los acontecimientos; por su parte Buyng-Chul Han (2018) estima que "el aroma del tiempo" se advierte precisamente al construir la narrativa del acontecer, que deviene en historia. Por ello, las diversas formas temáticas que asume la narrativa inducen una lectura donde el mundo narrado encuentra una lógica de sentido, en que las referencias extratextuales se asimilan a la categoría de "mundo posible" (Dolezel). Así, el verosímil literario, el efecto literario de realidad, se funde con el verosímil referencial, asunto que involucra la puesta en evidencia de información cuya validez se sostienen en la memoria del acontecer, el hecho que se registra y documenta la factualidad, aunque se la cuestione en la operación de lectura, o bien los mismos escritores se encarguen de afirmar que todo es ficción, incluso los nombres reales que aparecen en la narración.

Ese aspecto cobra gran relevancia, por cuanto el orden narrativo propuesto por los novelistas que inician el siglo XXI en Latinoamérica obedece a nuevas lógicas de lo imaginario, donde es clave la posición enunciativa que experimentan, una variable que involucra - a lo menos- considerar las condiciones de base que marcan el oficio de escribir y aspectos generacionales, en otras palabras, el modo en que se discute $-\mathrm{o}$ no- la tradición narrativa. De hecho, a juicio del mexicano Pablo Raphael, hay una serie de libros que "contienen historias redondas, deshilvanadas pero redondas, cuyas anécdotas apelan a la sencillez, pero al mismo tiempo están dotadas de una poderosa sabiduría" (2011: 225), afirmación que despeja la idea de una literatura incomprensible, aunque sí de formas experimentales.

En términos de escritura, un rasgo específico que observamos es que la construcción de esas narrativas muestra el ensamble o desplazamiento de fronteras discursivas, con zonas de "entremedio" que conectan campos emergentes en una temporalidad imaginada, en la cual convergen la ficción literaria y el pulso de la Historia. Desde esa perspectiva, la naturaleza del discurso novelístico adquiere una dimensión significante, entendiéndose que en la narración se

\footnotetext{
${ }^{\mathrm{I}}$ Evocamos con ese término a Michael Foucault y su libro El pensamiento del afuera (2014). Valencia: Pre-textos, I2-I3.
} 
encuentra un modo de referir y comunicar algo a otros; en su reverso, muestra registros de la experiencia colectiva, en un transcurso de representaciones que se articulan en torno a ejes de tensión y a una espacialidad estructuradora, que denota el potencial repertorio de enunciaciones literarias en distintas dimensiones, con las cuales el lector entra al campo de lo imaginario.

Ese ensamble de fronteras discursivas pone en funcionamiento diversos signos culturales, insertos en el mundo narrado, que remiten a cuestiones artísticas, vida política, nombres de películas y personajes, programas de televisión, música o letras de canciones, información periodística, lugares, crónica policiaca, etc. Por eso mismo, si bien se trata de una estrategia escritural, exige al lector a (des)articular el hilvanado textual del relato que conduce la voz narrativa, llenando las fisuras del afuera, particularmente la insuficiencia de los discursos sobre el mapeo de conflictos humanos en Latinoamérica. Desde esa mirada, la lectura de marcas de época confluye en la significación del tiempo evocado en el relato, las huellas de un tiempo que se expande, se intenta burlar o que se consume en la inevitabilidad del olvido. Son "indicios" (Todorov, 1992), que demandan considerar una materialidad imaginaria, cruzada de sentidos, disponiendo al lector el encuentro con una narrativa cultural, originada por un transcurso y la memoria social. El aspecto clave consiste en que su legitimización pública desestabiliza los relatos hegemónicos de la historia, al insertarse en el imaginario colectivo, que en definitiva absorbe el valor simbólico de esas narrativas y que moviliza una imagen de la realidad.

Sumado a lo anteriormente dicho, un segundo ángulo clave es que las nuevas narrativas introducen diversos tipos textuales al relato, que más allá de la estrategia novelesca, demandan asumir lecturas de mayor complejidad, cuestión que si bien en ningún caso resulta absolutamente inédito, da forma a estéticas que proponen otras codificaciones para constituir el mundo narrado. En definitiva, se trata de elaborar líneas de sentido, considerando el valor semiológico de esas textualidades, incorporadas al campo literario como estrategia de ficcionalización. El origen de ese fenómeno puede explicarse, por ejemplo, en la idea de quiebre con los géneros canónicos, en tanto la lectura nos muestra que en el flujo narrativo aparecen textos testimoniales, notas biográficas, cartas, información histórica y de conflictos políticos, crónica, notas de prensa, crítica cultural, ensayo, guion cinematográfico o televisivo. En definitiva, se trata de textualizaciones que surgen de diversas prácticas y formas de producción discursiva y cultural.

Esto nos lleva a plantear que la transtextualidad es un rasgo diferenciador del proceso narrativo latinoamericano de este periodo - o a lo menos de una de sus líneas-, por cuanto la narración está orientada por la transversalidad de diversas formas textuales que modelan el relato, 
donde el rasgo dominante es el modo novelesco ${ }^{2}$. En esa condición, el mundo narrado rompe su linealidad y se constituye en una red de sentidos posibles, en la que cada "nudo" conecta con otro y "se sitúa por relación a todos los otros en un espacio que los contiene y los separa al mismo tiempo" (Foucault, I2). La semántica del texto - acorde a esa idea-, se tematiza en torno a la relación de conflicto de los efectos de la modernidad, donde son recurrentes la neourbanización segregante, las diferencias sociales y culturales, utopías fracasadas y crisis generacionales; la tecnologización del bienestar, espacios laborales opresivos, miedos sociales (pobreza, violencia, acoso, discriminaciones, humillaciones, olvido); criminalidad organizada, migraciones, tráfico de personas.

En ese entendido, si la cultura latinoamericana en las últimas décadas tiene hitos que signan distintos momentos de su proceso, las prácticas narrativas operan entonces como una instancia de registro de las tensiones históricas y políticas que la enmarcan. En tal escenario, los sujetos reales -en la perspectiva de la presencia autoral de la escritura-, asumen las transformaciones que conllevan esas tensiones, que tienden a diferenciarse en la creación de los mundos ficcionales, entregándole una dimensión testimonial a la escritura, evidenciada en la figura del narrador, que posibilita la entrega de una mirada interior a la realidad.

En la visión del proceso literario latinoamericano, hablamos de una narrativa cuyo diseño evidencia que los factores operantes de lo mágico y lo maravilloso fueron desplazados por la contingencia histórica ${ }^{3}$, además de otras variables asociadas a la neourbanización tocada por las tecnologías. Esto abre un campo de otras concepciones sobre la vida social y cotidiana, asunto que sin duda impactó en el paisaje formativo de los escritores emergentes, quienes anticipan las variantes de nuevas tradiciones literarias que desplazan la anterior.

Esta materia conduce a diversas propuestas de pensamiento crítico, que amplían el espacio de los estudios literarios, en tanto las estrategias narrativas y la tematización demandan un ejercicio intelectual con nuevas exploraciones, que develen el alcance creativo y estético de esa escritura. En otro sentido, es un campo que hace entrar al debate el aporte de narradores emergentes con una actividad escritural que se desmarca o cuestiona la tradición literaria

\footnotetext{
2 Si bien el concepto es asociable al planteamiento de Gerad Genette, quien lo vincula a distintas formas de "trascendencia" en el texto (hipertexto, paratexto, metatexto, etc.), para oponerse a su inmanencia, en este trabajo lo enmarcamos al proceso de significación dominante dada por el empleo de distintas formas textuales, que en el caso de Monge tiene un carácter evidentemente literario. Ver: Genette, Gerard (1985). Palimpsestos. La literatura en segundo grado. Madrid: Taurus.

${ }^{3}$ Un importante trabajo sobre el contexto político y cultural que desmanteló el predominio del boom y llevó al fin del "realismo mágico" puede leerse en "Edipo en tiempos posauráticos: modernización y duelo en el boom hispanoamericano", de Idelber Avelar (20iI) en su libro Alegorías de la derrota: La ficción postdictatorial y el trabajo del duelo. Santiago: Cuarto Propio.
} 
inmediata (una narrativa posbolaño, acorde al juicio de los mismos creadores), considerando que su etapa formativa, por época, asimila el telón de fondo de los proyectos culturales y políticos, interrumpidos de modo violento, particularmente en el último tercio del siglo $\mathrm{XX}^{4}$. Se trata de un componente que permea la ficcionalidad, de modo que esta alcanza una conexión con posibilidades de narrar un espacio de poscrisis.

Dada la envergadura que alcanza actualmente esa producción, constituye a esta altura un campo particular de estudio, explicable por cuanto configuran un espacio de referencia en que las palabras exceden el soporte que las contiene, activando de ese modo un vínculo entre discurso narrativo y realidad. Entonces, se da la paradoja de escritores que revisitan formas tradicionales de narrar, ampliadas con recursos técnicos del mundo contemporáneo, para referir a distintas crisis sociales, que proveen de una materialidad con la cual es posible nutrir el mundo ficticio, donde se reconocen los efectos de la urbanización, los totalitarismos, asesinatos masivos, migración forzada por represión política o por la búsqueda de mejores condiciones de vida.

Para el tema de este trabajo, hemos hecho presente la trayectoria de un mundo narrado en que se alterna la crueldad del tráfico de inmigrantes a quienes se asesina y una historia de amor en Las tierras arrasadas (2015) de Emiliano Monge, donde los seres humanos devienen en una mercancía transportable.

\section{LA FICCIÓN DE LA NO-FICCIÓN EN LAS TIERRAS ARRASADAS}

La ficción trabaja con la creencia y en este sentido conduce a la ideología, a los modelos convencionales de realidad y por supuesto también a las convenciones que hacen verdadero (o ficticio) a un texto. La realidad está tejida de ficciones" (Piglia; 200I: IO-II).

El planteamiento escritural de Las tierras arrasadas - pensado en los conceptos previos-, se inscribe entre las líneas de la narrativa latinoamericana del siglo XXI. Es central en ese ámbito anticipar que el mundo narrado se construye sobre un espacio geográfico abierto y dinamizado por la violencia, donde las víctimas fatales de su práctica son emigrantes provenientes de algún lugar de centroamérica que transitan hacia un utópico norte. Sus victimarios, bandas organizadas de tráfico humano, cuyas rivalidades a muerte encierran conflictos de liderazgo y de poder, donde el dominio

\footnotetext{
${ }^{4}$ En ese panorama, aparecen nombres como Jerónimo Pimentel, Alejandro Zambra, Patricio Pron, entre muchos otros escritores del siglo XXI, sin olvidar la notable producción de narradoras como Nona Fernández, Mariana Enríquez, Wendy Guerra, por mencionar algunas de ellas. Si los consideramos como grupo, es posible advertir los rasgos narrativos y textualidades de las que se habla en este artículo, que por lo demás ellos mismos refieren en congresos y publicaciones de distinto alcance académico y cultural.
} 
territorial se fusiona con el control sobre esa mercancía humana. Esa forma dual de la violencia (entre bandas y hacia los emigrantes), constituye precisamente el eje que moviliza los distintos planos de acción con los que Monge modela la historia narrada en una compleja trama, en la medida que abarca un conjunto de variaciones temáticas y de una textualización que experimenta con las formas del relato y la voz que narra.

En principio, es una violencia que se distancia de la teoría política o de explicaciones ideológicas. No se trata de un acontecer en que haya una confrontación explícita entre conglomerados que divergen en sus concepciones y procuran dominar mediante mecanismos que legitiman su poder, o imponiendo un sistema político que usurpa un gobierno, cuyos efectos son habitualmente represión, muerte y exilio, como ocurriera hacia el último tercio del siglo XX en países de Suramérica. Se alude, en este caso, a un problema crítico que se originó en el contexto de las decisiones gubernamentales en México hacia el año 2006, destinadas a controlar los carteles de la droga, lo cual implicó militarizar un rol de orden policíaco, con el fin de cercar las zonas de influencia que alcanzaba esa actividad delictual.

En ese marco, surgen grupos criminales que comienzan a controlar el histórico tránsito y desplazamiento de migrantes hacia Estados Unidos, quienes se transforman en una mercancía que se transa, a la que se niega su condición humana, hasta incluso aniquilarla5. Precisamente, Alina Peña Iguarán expresa cómo el trasfondo de la novela de Monge despliega un problema nacional:

la industria migratoria en el contexto mexicano [...] controlada, en buena medida, por el crimen organizado. El negocio del trasiego de cuerpos ha proliferado y curiosamente "regula" los tránsitos del territorio. En este sentido, el narcotráfico no distingue, en su comportamiento empresarial, si trafica armas, drogas, maderas, cuerpos (2018: I42-I43).

Si hubo un sistema represivo ideado para contener la expansión de los carteles, en su reverso potenció que se profundizaran espacios y formas de cultura delictual en las villas con sus propios códigos de convivencia, que coexisten junto a los pobladores. El problema de mayor alcance fue que, además, se acentuó el poder de bandas organizadas, que hacen visible su influencia en el comercio de las adicciones y las disputas por el control territorial mediante la violencia armada, apareciendo así grupos que controlan, dominan y comercian los desplazamientos masivos de personas, particularmente centroamericanos y de zonas fronterizas con Estados Unidos, quienes intentan zafarse de las condiciones de pobreza, buscando opciones de mejor calidad de vida.

\footnotetext{
${ }^{5}$ La información oficial mexicana señala que las primeras muertes colectivas de migrantes, que alcanzaron gran impacto mediático, ocurrieron el año 20Io, al encontrarse $7^{2}$ personas torturadas y asesinadas en Tamaulipas, originarias de Honduras, El Salvador, Guatemala, Ecuador y Brasil. Desde esa fecha, se estima que han muerto más de 4I mil personas, en tanto que hay casi 37 mil NN. Ver: Alina Peña Iguarán (2018). "Vidas residuales: el arte en los tiempos de guerra. Las tierras arrasadas (2015) de Emiliano Monge". Revista de pensamiento, crítica y estudios literarios latinoamericanos. Vol. I7.
} 
En esa línea de sentido, es perfectamente válido aproximar el libro de Monge a una lectura política con un implícito ideológico, en la medida que refiere un problema que arranca de decisiones de un gobierno y que afecta a grupos humanos que transmigran, exigidos por sus privaciones, la violencia y las múltiples formas de segregación que eso genera. Son un efecto residual de estrategias gubernamentales fallidas que producen una catástrofe de ecología humana, transformada por los medios en hecho político-noticioso y un problema de fronteras, o la condición de subalterno - siguiendo a Gayatri Spivak-, un sujeto sometido a un campo de poder y exterminio. En términos de población, es la ruralidad que — según Monge- forma un espacio de problemas de larga permanencia en México, aunque su naturaleza y perspectivas de mundo haya asimilado distintas formas de lo moderno, alejada ya del agrarismo revolucionario. Desde otro ángulo, en la (ficticia) maquinación de exterminio participan no solo individuos criminales, sino que también representantes de jerarquías sociales, como militares, policía e incluso sacerdotes, en una red de calculadas decisiones para lograr el dominio territorial y beneficios económicos en un montaje de venganzas.

El relato opera entonces mediante un fusionado de tiempos y acciones, que Monge sobrepone, acertadamente, en distintos planos de profundidad, activando rutas de lectura. Un efecto de ese diseño es que el suspenso y la intriga se articulan en núcleos independientes y en temporalidades simultáneas, operando como un telón de fondo recíproco que explica el destino imaginario de los personajes, suspendido por la entrada en nuevas líneas de acción.

Centralmente, un primer plano generador consiste en la historia de los protagonistas de la novela, Estela y Epitafio, "esta mujer y este hombre que se quieren hace tantos años, tanto" (Monge, 20r6: 30$)^{6}$, quienes en su autoimagen de rudeza y de liderazgo fuerte hacia los integrantes de su banda, se resisten a asumir o explicitar la necesidad afectiva del otro, el nexo vital que los une y, en el caso de la mujer, la evidencia de su incipiente preñez.

La historia que los une -el pasado ficticio que los conecta en la infancia precaria, plena de necesidades y desafectos-, los sitúa ahora en la complicidad consciente de una acción que pone en el relato la doble intriga, donde la voz narrativa se desplaza entre el Libro de cada uno y el Intermedio destinado a la trama que los sitúa protagonizando un plan furtivo en su contra. El otro campo de esa trayectoria paralela es el desplazamiento fatal de los emigrantes, cuya experiencia límite se desborda en distintos cuadros de violencia y horror, que se sostiene más que todo en la fuerza del registro testimonial que Monge insertó en la narración. Es una marca que trae consigo la

\footnotetext{
${ }^{6}$ En las citas que siguen, se indicará solo la página de la novela y la edición chilena de 2016.
} 
ficción de la no ficción a la novela: una cantidad alta de emigrantes transportados en tráilers por México hacia el norte; una masa de seres innombrados que constituyen un número, un valor, una catástrofe, una inmolación; la persistencia de un fondo en que la pobreza y el desamparo convergen y son falsamente apoyados por grupos de traficantes humanos, para movilizar la fuerza de su exterminio, una "máquina de muerte", que se anuncia en los claros de la selva o en el territorio rocoso y baldío de la sierra.

La recomposición de ese nexo entre la pareja consiste no solo en descubrir su infancia compartida y traumática en una casa de acogida para niños, administrada por el padre Nicho, con el engañoso nombre de El Paraíso, sino que se agrega su capacidad de liderazgo en la conducción de una banda de traficantes, algunos de los cuales confabulan con el fin de terminar el dominio déspota mediante una estratagema cuyo fin es aniquilarlos, coordinada a distancia usando aparatos telefónicos inhalámbricos:

Es lo opuesto, exactamente, que sucede allá en la sierra, en la casa que corona El Teronaque, en lo más hondo de la selva y en el hospicio El Paraíso, donde Estela, por un lado, Epitafio, por el otro, los dos chicos que se fueron de la casa hace una hora y el padre Nicho apresuran sus palabras: quiere ella estar segura cuando llegue a La Cañada y por eso sigue hablándole al Chorrito; él desea estar manejando ya su tráiler y por eso está gritándole a los seres vueltos sombras que han perdido ahora sus cuerpos y que si alguien intentara aquí abrazar no asir podría... (133-134) ${ }^{7}$.

En ese marco de análisis, el realismo ficticio y fragmentado de Monge, operando sobre el documento testimonial, construye un esquema narrativo que valida el "afuera", la dimensión trágica de la realidad factual de personas que recuperan la voz de una experiencia límite donde no hubo elección. Desde otro giro de página en la lectura, la oralidad real del testimonio postrauma que se registra en el texto periodístico, Monge la recodifica en su proyecto de escritura: ese "afuera" oral deviene en la ficción de la novela y la novela se proyecta y valida lo real-imaginario construyendo una narrativa de la crueldad:

Nos metieron en la casa que apestaba a cosa muerta... nos volvieron a pegar y a quemar... "el que se mueva lo vamos a matar"... nos pidieron nuestros números, de nuestras familias... les exigían diez mil dólares... se reían de ellos y nosotros... nomás por eso hablaban... sabían que no obtendrían nada" (78).

De hecho, la interlocución del testimonio es incorporada al relato, luego es de suponer que el narrador-autor regula el habla del emigrante anónimo-real. Por otra parte, el narrador básico activa una doble voz (el raptor), a la que se adiciona la de Dante, visible textualmente en la tipografía. En los términos de Jablonka, la "ficción de método", cuando problematiza la narración de la historia, se legitima como una genuina ficción, aunque el acontecer refiera a lo real.

${ }^{7}$ Las cursivas son del texto original, en todos los casos (N. del A.). 
La imagen visual de personas que se movilizan y desplazan con su imaginario, el tránsito nómade que funda y territorializa, ese extremo de avanzar a la intemperie, constituye otra "comunidad imaginada" (en símil con Benedict Anderson), pero que desborda los límites, sosteniéndose, ya no en la utopía de una tierra promisoria, sino en la voluntad de escapar y librarse de la muerte. Así pues, lo que construye Monge es un guion implícito en que los roles se distribuyen sin que los personajes lo sepan, una licencia del narrador que despliega el panóptico de la crueldad en la estructura de la novela: planos y cuadros simultáneos de acción, la cita literaria, la subjetividad imaginada del victimario, el amor y el deseo de los amantes, la pausa del plano detalle previo a cambiar el foco narrativo y seccionar la novela en el Intermedio que lleva a un nuevo capítulo:

Antes de que Estela se recueste en el colchón desvencijado, el padre Nicho deja el cuarto y precipita su avanzar por los pasillos y escaleras del hospicio: él tampoco quiere que comiencen en el sótano a marcar a los pequeños sin ser él quien lo haga, sin ser él pues quien empuñe su punzón en ese sitio al que dirige su camino.

Estela, mientras tanto, aprecia acostada en su cama, las seis vigas que han atestiguado tantas veces y que tantas otras veces lo han visto a ella despedirse del desvelo y la vigilia. Cerrando los párpados sin darse cuenta apenas, cuenta, la que adora a Epitafio se sumerge en la inconsciencia... (93).

Entonces, dada esa estrategia narrativa, la voz de los migrantes se transforma en figuras secundarias y fantasmales, de las que emerge solo el murmullo y los gemidos en el tránsito hacia una zona de sacrificio, en la medida que la unidad del mundo referido opera sobre una intriga que proyecta el suspenso con la historia de Estela y Epitafio, donde esas voces de citas fraccionadas denotan la composición mayor de un escenario, entre la abundancia de la selva y el espacio desierto, en diálogo con la crudeza humana.

En el espacio reverbera únicamente la veloz metamorfosis de las horas: los graznidos de los grajos dejan su lugar al ulular de las lechuzas, cubren con su manto las chicharras a los grillos y los tapires, ocelotes y coyames callan para que hablen los coyotes, los pavones, los zorros (Irg).

La transtextualidad diseñada por Monge -sostenemos-aglutina elementos dispersos y centra las subjetividades en la acción narrativa, entregando identidad a las voces, donde la operación de lectura demanda establecer las coordenadas que las unen; por otra parte, los "ensambles" y fusionados distribuyen temporalidades discontinuas, generando suspensiones y paralelismos, vacíos textuales que desafían al lector a preguntarse y a cuestionar el límite de lo humano. Su acto de hacer literatura es revelador: la exterioridad se agrupa en su condición de "enunciados" provenientes de un "archivo" que los legitima como referentes colectivos de un hecho verdadero, proyectándose sobre un imaginario que da forma a una narrativa de la migración. En otro sentido, esos registros de una evidencia periodística o incluso jurídica, al enmarcarse en la 
composición de la novela, modifican su estatuto real y exceden la memoria de un narrador individual, constituyendo un pasaje a una formalización textual colectiva, en que la validez de las palabras se escapa de su funcionamiento meramente imaginario y transtextualiza su sentido.

De ahí que el archivo de la narrativa en Monge sea una "fuga" del modelo novelístico, al operarse con cambios en el espacio textual (la ficción) y no discursivo (la realidad), distanciados de las formas imaginarias del encantamiento marravilloso, pues llevan a que el efecto de lo literario converja en estrategias en que la textualidad sobrepone los referentes en planos de sentido, produciendo que el registro testimonial opere sobre el plano de la narración y el entramado de un intertexto. Las fronteras discursivas de la ficción entonces mueven y potencian la lectura cruzada de los signos, a su vez la legitimidad de los componentes explicativos de una noticia, que no es sino la cruel desaparición y muerte de los inmigrantes.

\section{LA ACCIÓN EN LOS INTERMEDIOS}

Yo no creo en la literatura o en el arte que, bajo el signo de lo que sea, se fundan en la asimilación sentimental, en la cosquilla emotiva. Creo, por el contrario, en la literatura y en el arte que se oponen a la realidad, que la agreden, la transforman y, al hacerlo, la revelan, la afirman. (Carlos Fuentes).

Por la organización de la novela y su transcurso narrativo ordenado en libros e intermedios, la accesibilidad a los espacios ficcionales demanda un acto de lectura intenso. Eso implica articular, desde un inicio, el ámbito de sus variados referentes para acercarse a sus eventuales significaciones, que en el mundo narrado disponen secuencias lineales que se rompen y abren espacios y acciones paralelas, recapitulaciones, condensación o dilatación de la temporalidad. La relación de esos componentes de escritura orienta el sentido del suspenso y de la intriga que subyace en la historia narrada, donde la voz narrativa oscila en una multiplicidad de enunciaciones, que después de todo aproximan a la experiencia interna de los personajes en escenarios de violencia.

La puesta en perspectiva del fondo que moviliza el acontecer, el mapa (imaginario) de los libros e intermedios, fuerza a diagramar el despliegue de acciones sobrepuestas, marcadas en múltiples ocasiones por el "mientras tanto" que enuncia el narrador básico, con el tono de ironía, pausa ("en esta parte") u omnisciencia que pone en alerta. Atendiendo a ese modo de operar la narración, se descubre que hay acciones que continúan transcurriendo en un plano oculto (un recuadro imaginario), no obstante acontece que la misma secuencia hace visible el exterminio de "losqueignoransunombre", que el narrador inscribe alternadamente con la conciencia de Lacarota 
(Epitafio), quien se mueve proyectando su relación con "oigosololoquequiero" (Elisa) y la incógnita de sus temores:

...Epitafio vuelve a preguntarse qué le habrá hecho él a Estela y no halla calma hasta que no intenta
engañarse: debe ser por Cementeria ... estás nerviosa por lo que hizo esa pendeja y como siempre yo
lo pago. En el corazón del matadero, mientras tanto, los muchachos que obedecen a Lacarota siguen
castigando a los hombres y mujeres que vinieron de otras tierras (77).

En esa construcción narrativa, según se expresó, opera una sobreposición de dos líneas de sentido: el tráfico de emigrantes que han sido engañados para venderlos o intercambiarlos por mercancía ilegal (armas, drogas), y el amor entre los líderes pandilleros, quienes protegen el dominio territorial de las bandas que dirigen. Desde ese espacio de acciones, se desarrolla la moral del traidor y la aparición de antihéroes. Su materialización será la violencia genocida y el mandato de roles canallescos que obligan a violentar a los "sin alma".

Ese es el oficio que Monge activa con Mausoleo, el migrante de gran corpulencia física y antiguo peleador, que Epitafio elige y alecciona en la barbarie para controlar al grupo, consecuentemente es un privilegiado que se convierte en un engranaje más de la máquina de muerte, el vigilia de "los "sin Dios" y que "han perdido toda esperanza". El rol que asume lo resta de los masacrados y le obliga a ser el guardián que se impone a sus semejantes, es también el protagonista de un espectáculo donde lucha a muerte y se apuesta por su victoria, que culmina en su convencimiento de que imponer orden supone la acción brutal:

Sintiendo que su brío sana las heridas que le abrieran sus temores, el que entre ciegos es ahora un nuevo ciego llega hasta la masa de hombres y mujeres castigados y humillados, distiende por primera vez en todo el día su gesto, agarra a un viejo por el cuello, lo arrastra varios metros, lo somete contra el suelo y señalando el resultado de su náusea ordena: jlimpia ahorita tú esa mierda (80).

La conciencia transformada de Mausoleo se despliega con claridad en el Primer intermedio (Así se derrumbó el horizonte), que marca una transición en la trama de la historia, o una pausa en la intriga de la traición, en donde se redefine el personaje, quien ya no es masa, sino alguien que observa y debe actuar con absoluto cálculo en su función represora. Más allá de una estrategia de composición, la metanarración hace operar una línea de conciencia reflexiva, donde el lector es desestabilizado imprevistamente, cuando se le anticipa que todo termina de modo trágico y que los personajes lo presienten (Estela). Es el paso a un capítulo-transcurso de las acciones que lleva al montaje de un escenario posterior (prolepsis), aunque sigue escuchándose la voz de "los que fueron arrancados de su alma" y las citas de Dante: 
Esta emoción tan nueva en él como el impulso que lo hizo arremeter contra la niña, y como esa voz que le habló en la sala, se convierte en convicción cuando, recargándose de nuevo en su puerta, Mausoleo siente que se vuelven sus temores puro orgullo: es él quien hoy vigila a los hombres y mujeres que además de que no pueden ya esperar nada del cielo no debieran esperar nada tampoco de esta tierra (99).

Esa posterioridad conduce a un foco de acción que da forma al Segundo intermedio (Volverán la luz y el fuego), cuyo "efecto de presencia" muestra una ruptura en los límites de lo inhumano, el "afuera" imaginado del transcurso que muestra en su desarrollo imaginario la violencia genocida, un holocausto en el cual intervienen otros victimarios, quienes asumen, fríamente, que su rol forma parte de un negocio que incluye la tarea adicional de limpieza y aseo: las formas de ocultar-desaparecer una existencia volatizada en el fuego, el origen de los desaparecidos en la frontera norte. Es un infierno desatado en la inmensidad de la selva, que desplaza la estética macondiana, donde lo incomprensible aparece desde la activación de una pesadilla originada por la voluntad humana, antes que por una materialidad desconocida y misteriosa a la cual se arriba como un castigo:

Cuando ha lanzado al fuego ya todos los brazos que cargaba sobre el hombro, Merolico alza del suelo el bidón de gasolina que dejaron los hermanos junto al tambo y rociando la lumbre atestigua cómo su violencia, nerviosa y poderosa, se levanta enfurecida: así se levantaban, en la selva de las tierras arrasadas, las violencias que acabaron con aldeas, villas y pueblos (251-252).

Los intermedios de la novela, operados desde la multiplicidad de voces y perspectivas, conducen a observar un montaje y fusionado, en que la aceleración de las acciones se sintetiza en un paneo (un "storyboard" cinematográfico), cuyo plan de desarrollo ya ha sido realizado y que el narrador básico resume, anticipa y pone en diálogo, sistemáticamente, con el imaginario del personaje. Si es una estrategia, recompone la historia, la recuperación de la memoria y el trascurso narrado; vista como apelación al lector, es la actualidad de un presente que lo pone en tensión ante lo real-imaginario y el afuera, el efecto de una narrativa que cuestiona la suficiencia del texto y la simple referencialidad literaria, al introducir el registro de la violencia en la voz testimonial de los migrantes que lograron escapar de la muerte:

Vivía en casa de mi tío ... mis padres ya no estaban ... vivían también ahí mis hermanos ... mis primos y otras tías se habían ido a Oklahoma ... dejé mi monte

y mis cafetos ... para andarme allá a las vías ... no le dije

nada a nadie ... ni a mi mujer le dije nada ... tenía miedo ... no sabía ... pero ahora entiendo ... el miedo es esto (I89)

Entonces, si la globalización conduce a restar el carácter nacional de la literatura, paradojalmente, Monge - a contrapelo de los tiempos- construye en Las tierras arrasadas un 
mundo literario que (de)muestra diferenciaciones que obedecen a problemas locales, en otras palabras, desmiente que la pertenencia a los circuitos de lo moderno desplace las diferencias. No obstante, en verdad, la cuestión crítica de fondo que se desarrolla en la novela es otro asunto: el interés económico y de mercado, una marca muy de época, da forma a la violencia, en que se procura alcanzar el cumplimiento óptimo de una tarea, aunque sea al servicio de una empresa de muerte, consecuentemente, se subvierte y redefine la construcción del poder, que ahora es el dominio de cuerpos y territorios. Mabel Moraña, precisamente, examina variables que explican o direccionan la compleja transformación de la violencia en el espacio latinoamericano, en un momento en que las lógicas de los equilibrios políticos tienen otra dirección, con procesos sociales que ponen al individuo en el centro del interés público:

[la actual violencia] Redefine las ideas de lealtad grupal, éxito, poder y valor personal, creando una adecuación otra entre medios y fines. No intenta superar ni reemplazar con algo mejor los mitos de la modernidad, sino que los expone y los extrema, como en un simulacro monstruoso en el que mundos paralelos reproducen perversamente, en la clave de un desesperado y desesperanzado individualismo, los ideales civiles de las burguesías nacionales: el ideal de la conquista de mercados (narcotráfico), la sustentación de identidades territorializadas (pandillas), el poder de detentar la violencia para la consecución de fines autolegitimados (2006: 188).

En ese sentido, es posible pensar que la novela de Monge activa un despliegue de enunciaciones como un archivo, en la perspectiva de Foucault, singularizando un campo de relaciones desde la ficcionalidad, en que el lector recoge e integra una narrativa que discute la hegemonía del relato social, para centrarse en la dimensión existencial de los sujetos reales, donde la voz narrativa mimetizada (ficticiamente) en el carácter de los personajes mueve la historia y el trauma; la intriga cuyo eje de acción remite a héroes marginales traicionados — la venganza- y la pérdida de su liderazgo y dominio territorial.

En ese diseño de lo real-imaginario, los ritmos y espacios temporales ficcionados desde la voz plural y también externa al sentido interior de la historia narrada, coronan el efecto de incertidumbre que conduce la intriga y la tensión narrativa, la que abarca lo que acontecerá con dos líderes enamorados y el destino de un colectivo humano. La anticipación (prolepsis) confirma una artimaña que pone al amado ante la fatalidad de su muerte, el anverso del aniquilamiento colectivo, proyectado en esa otra fatalidad de los amantes cercados por la trampa de su propia pandilla en territorios de geografías opuestas: la selva y la sierra:

Este tráiler que dejó hace un rato el vasto y casi enteramente despoblado Llano de Silencio que une el sur y al centro de la patria en que nacieron Epitafio, los dos chicos de la selva y Estela. Esa mujer que allá en el fondo de La Caída, recostada sobre el suelo de la casa del trillizo que se fue un día a las montañas, vuelve en sí un instante y balbucea, extraviada en su maraña de dolores y 
temores: también a él... van a dejarme... a él a matarlo... sin coordenadas... tengo llamarlo... nos traicionado... no sin mapa... sin él no quiero... sin mi Epitafio (3Іо).

En ese marco, la novela puede leerse como la historia de un amor y la confabulación que busca la muerte de los enamorados; no obstante, en más de un sentido, la variante insospechada de sus órdenes y decisiones que terminaron con las muertes de "los sinnombre", abre un espacio a las relaciones de dominio y poder, que en definitiva movilizan a los personajes y explican las confrontaciones, que efectivamente terminan con la inmolación deliberada de Epitafio y la autoceguera de Oigosololoquequiero, que no acepta la visión sin la presencia de su amado y que tampoco puede ver el final de toda la historia real-imaginaria:

Saltando los cuerpos de los chicos de la selva, que acaban de dejar el claro Ojo de Hierba como acaban de dejar la historia de Epitafio, la historia de Estela y ésta que es su propia historia: la historia del último holocausto de la especie, los que obedecen a ese hombre que ahora está bajando de su enorme camioneta llegan hasta el sitio donde yacen los sin Dios, los levantan uno a uno y les encajan los hocicos aún humeantes de sus fierros: también sucede por la noche, pero esta vez es por el día. (34I).

De ese modo, se asume el destino fatal que conduce la destrucción en el enfrentamiento a balas entre bandas: la pareja de enamorados, los emigrantes que son víctimas de la fuerza de la violencia, los intereses de poder, la incertidumbre del final abierto "y un norte que no habrá de llegar nunca" para los emigrantes.

\section{CONCLUSIONES}

Mediante el despliegue de una situación de conflicto que tensiona la acción del mundo narrado, Monge experimenta el cruce de fronteras discursivas; es una forma escritural que muestra la voluntad de narrar un escenario múltiple y las voces que lo enuncian, entre la cuales el mismo narrador se implica, de modo que si aparece la invención de "ficciones de método", su efecto de historia remite a "un afuera" y a un acontecer que permanece. Kundera señala que la novela revela la contradicción, la incertidumbre, algo que - pensamos_-, se evidencia en el modo que transcurre y termina Las tierras arrasadas: hay un espacio de poder y dominio sin márgenes.

Acorde a esa situación, la novela hace evidente una discusión con la insuficiencia de la historia legitimada para abordar el acontecer de un desplazamiento humano, que niega y excluye la experiencia e imaginarios que portan los sujetos, solo revisitada en los lectores o audiencias mediatizadas, que asimilan una narrativa del miedo y del despojo vital. Es una narrativa que muestra el desplazamiento de sujetos sociales, producido por la descomposición de un mundo y sus construcciones sociales; en ese sentido, vemos que Monge se mueve con la historia del 
silenciamiento, las acciones que ocultan o diluyen las imágenes de la realidad, un patrón reiterado que termina en la imagen de narrativas de la violencia, la desesperanza y la pérdida de un destino, la distopía que desplaza la felicidad y la plenitud.

Interrogarse sobre el propósito de ese discurso novelesco conduce a reflexionar sobre la función del relato, donde opera el implícito del alcance (o calce) de la narratividad, con alguna certeza que pueda encontrarse en el texto, en la premisa de que hay proximidad con un referente externo - el afuera, el lector-, con lo cual se pone un arco de sentidos que rompe la suficiencia del texto, un punto de fuga que obliga a mapear esas zonas de encuentro en el despojo y la muerte anónima, movilizando así la ética de las subjetividades que demandan amparo y cobijo al otro.

Desde otro ángulo de análisis, vemos que la exterioridad de la historia y sus vías de legitimización activa distintos planos de relaciones con la memoria, singularizada en el hallazgo de la no-ficción en la ficción. Entonces, la ficción del archivo en la novela propicia una pragmática literaria situada en la historia, que llega al lector como una dispersión del relato que se sostiene en el discurso que diferencia sujetos y tiempos, en que la figura ubicua de la voz narrativa controla los momentos asignados a los personajes, generando una estructura de evocaciones.

Eso se demuestra en que los textos presentan fronteras discursivas, (re)lecturas de signos sociales que transicionan, donde convergen el desplazado pulso vital de la historia y la ficción literaria, cuyo sentido generador pone en duda la significación cultural de la utopía y sus efectos en el imaginario colectivo.

La experiencia de lectura induce a observar en ese sentido el carácter que ha adquirido la narrativa latinoamericana del último tiempo, donde el mundo posible abre la opción de un ensamble del verosímil literario con un verosímil referencial. Por otra parte, la multiplicidad de formas en que se construye el relato conlleva a que lo imaginario ponga en tensión el mundo referido, de modo que se da forma a una narrativa cultural.

Por último, la transtextualidad narrativa de Las tierras arrasadas desafía comprender otras formas de composición. Esa complejidad induce a que se descubra la poética de su diseño y el efecto de presencia en una nueva literatura y una comunidad de lectores, por último, que abra también la discusión sobre las transformaciones de la época que vivimos. 


\section{REFERENCIAS}

\section{CORPUS}

Monge, Emiliano (2015). Las tierras arrasadas. Barcelona: Random House.

\section{ESTUDIOS CRÍTICOS Y TEORICOS}

Alvarado Ruiz (2015). "Escribir América en el siglo XXI: el Crack y McOndo, una generación continental". Revista Iberoamericana XVI, No 63.

Avelar, Idelber (20iI). Alegorías de la derrota: La ficción postdictatorial y el trabajo del duelo. Santiago: Cuarto Propio.

Barthes, Roland (200I). "El efecto de realidad", en El susurro del lenguaje. Buenos Aires: Paidós.

Benjamin, Walter (20Io). El narrador. Santiago: Metales pesados.

Doležel, Lubomir. (1998). Heteroscópica. Ficción y mundos posibles. Barcelona: Arcos libros.

Espezúa Salmón, Dorian (2006). "Ficcionalidad, mundos posibles y campos de referencia". Revista Dialogía, Vol. I.

Fernández-Lamarque, María (2016). Espacios posmodernos en la literatura latinoamericana contemporánea: distopías y heterotopías. Buenos Aires: Argus-a.

Foucault Michael (2014). El pensamiento del afuera (2014). Valencia: Pre-textos.

Genette, Gerard (1985). Palimpsestos. La literatura en segundo grado. Madrid: Taurus.

Iser, Wolfang (1989). "La realidad de la ficción", en Estética de la recepción. Madrid: Visor.

Guillermoprieto, Alma (201I). 72 migrantes. México: Almadía.

Han, Byung Chul (2018). El aroma del tiempo. Barcelona: Herder.

Jablonka, Iván (2016). La historia es una literatura contemporánea. México: FCE.

Moraña, Mabel (2006). "Violencia en el deshielo: imaginarios latinoamericanos post-nacionales después de la Guerra Fría”. Toulouse. Caravelle No 86 CMHLB.

Peña Iguarán Alina (2018). "Vidas residuales: el arte en los tiempos de guerra. Las tierras arrasadas (2015) de Emiliano Monge". Revista de pensamiento, crítica y estudios literarios latinoamericanos. Vol. I7.

Piglia, Ricardo (200I). Crítica y ficción. Barcelona: Anagrama.

Raphael, Pablo (20II). La fábrica del lenguaje, S.A. Barcelona: Anagrama. 
Robert, Marthe (1973). Novela de los orígenes y orígenes de la novela. Madrid: Taurus.

Soto, Simón (2016). "El terror se está llenando de preguntas". Presentación a Las tierras arrasadas. Udp, Dossier $N^{\circ} 34$.

Todorov, Tzvetan (1992). Simbolismo e interpretación. Caracas: Monte Ávila. 